\title{
THE NOVEL FRAILTY INDEX (NFI) CORRELATES WITH A VALUE OF PHASE ANGLE AND MNA IN HOSPITALISED AND FREE- LIVING ELDERLY - PRELIMINARY REPORT
}

\author{
E. Wernio ${ }^{1}$, J.A. Dardzińska1 ${ }^{1}$ H. Kujawska-Danecka² ${ }^{2}$ A. Hajduk², Z. Zdrojewski², S. Małgorzewicz ${ }^{1}$
}

\begin{abstract}
Introduction: To improve the quality of life and health of the elderly, attention is paid to the early detection of frailty syndrome. Unfortunately, one simple and practical screening tool has not been established yet. Recently came the proposal of the Novel Frailty Index (NFI) created by Yamada and Arai. Therefore, the purpose of this study was to assess the relationship between nutritional status and NFI of the elderly. Materials and methods: In a group of 67 elderly patients (27 hospitalised and 40 living in the home environment) we used the NFI and evaluated nutritional status with the use of full-MNA together with SNAQ (appetite questionnaire), manual dynamometry and bioimpedance analysis. Results: Based on the NFI results, frailty syndrome was diagnosed in more than half of hospitalised elderly. The syndrome was significantly less prevalent in free-living older people (15\% vs $63 \%, \mathrm{p}<0.001)$.We found the significant correlations of NFI values with age $(\mathrm{r}=0.031, \mathrm{p}=0.03)$, co-morbidity $(\mathrm{r}=0.295, \mathrm{p}=0.016)$, phase angle $(\mathrm{r}=-0.407, \mathrm{p}<0.001)$, full-MNA score $(\mathrm{r}=-0.515, \mathrm{p}<0.001)$. Conclusions: Our preliminary results suggest the relevant association between NFI results and age, phase angle as well comorbidity and nutritional status. So further evaluation of NFI as a screening tool for frailty syndrome diagnose is needed.
\end{abstract}

Key words: Novel frailty index, elderly, nutritional status, malnutrition.

Abbreviations: BIA: Bioelectrical impedance analysis; BMI: Body Mass Index; ESPEN: European Society for Clinical Nutrition and Metabolism; MNA: Mini Nutritional Assessment; MM: Muscle mass; MMI: Muscle mass index; NFI: the Novel Frailty Index by Yamada and Arai; SNAQ: Simplified Nutritional Appetite Questionnaire.

\section{Introduction}

The life expectancy is constantly increasing. By the end of 2014, the number of people reaching the advanced age constituted $22.2 \%$ of the Polish population. This percentage will increase and probably in 2050 more than $40 \%$ of all Poles will reach at least 60 years (1). To the important medical problems in the elderly populations belong also the frailty syndrome. It has recently attracted the attention of both scientists and clinicians. Unfortunately, there is still lacking a widely accepted definition of this state and, what is even more important, simple criteria for recognition (2). Recently a new tool to screen for frailty was developed by Yamada and Arai. It is the 5-question self-report questionnaire, that includes nutrition/shrinking, physical function, physical activity, forgetfulness and emotion/exhaustion. The answers are scored $0 / 1$ points, so the total score is from 0 to 5 points.

1. Department of Clinical Nutrition and Dietetics, Medical University of Gdańsk, Poland; 2. Department of Internal Medicine, Connective Tissue Diseases and Geriatrics, Medical University of Gdańsk, Poland

Corresponding Author: Jolanta Anna Dardzińska M.D., Ph. D. Department of Clinical Nutrition, Medical University of Gdańsk, Dębinki St. 7, 80-211 Gdańsk, Poland, e-mail: annadar@gumed.edu.pl, Tel/Fax: +48 583492723
Obtaining 3 or more points by the respondent is intended for the presence of the frailty syndrome (3). The new index was presented at the ESPEN (European Society for Clinical Nutrition and Metabolism) Congress in 2016 by Suzuki et al. as Novel Frailty Index (NFI) and frailty assessment based on it was associated with malnutrition and predicted prognosis in outpatients with chronic heart failure (4).

The inseparable characteristics of the frailty syndrome include the risk of developing malnutrition or existing malnutrition and related loss of muscle mass and function. For many years, the MNA has met expectations for a simple, useful tool for assessing the nutritional status of the elderly in clinical practice (5). Both parts of MNA (Short Form and Assessment) are characterised by high sensitivity and specificity (6).

So the aim of our study was to compare the results of the NFI evaluation with the effects of the traditional nutritional assessment using the Full-MNA, SNAQ, manual dynamometry and bioimpedance analysis in the group of elderly people. 


\section{Material}

The study group consisted of 67 elderly patients, including 27 patients hospitalised at the clinical hospital in Gdańsk, in the Department of Pneumology and Allergology and in the Department of Geriatrics. The control group was composed of 40 healthy volunteers in age $>65$ years old. The study was conducted in October $2016 \mathrm{y}$.

In Table 1 the characteristic of the study group is presented.

Table 1

Characteristics of the studied population

\begin{tabular}{lccc}
\hline & $\begin{array}{c}\text { All subjects } \\
\mathbf{N}=\mathbf{6 7}\end{array}$ & $\begin{array}{c}\text { Hospitalised } \\
\text { elderly } \mathbf{n = 2 7}\end{array}$ & $\begin{array}{c}\text { Free-living } \\
\text { elderly } \mathbf{n}=\mathbf{4 0}\end{array}$ \\
\hline Age (yr. mean $\pm \mathrm{SD})$ & $71 \pm 6.4$ & $73.9 \pm 7.6$ & $69 \pm 4.7$ \\
$\begin{array}{l}\text { Number of diseases } \\
\text { (median and range) }\end{array}$ & $2(0-7)$ & $3(1-6)$ & $2(0-7)$ \\
$\mathrm{BMI} \mathrm{kg} / \mathrm{m} 2$ (mean $\pm \mathrm{SD})$ & $27.6 \pm 5.8$ & $27 \pm 7.3$ & $27.6 \pm 4.6$ \\
\hline
\end{tabular}

Legend: BMI-body mass index.

The average age of hospitalised elderly was notably higher compared to those living in the environment (73.9 vs 69.0, $\mathrm{p}=0.012$ ), they had also more chronic disease than control group (3 vs 2, $\mathrm{p}=0.006$ ) (Tab.1).

Main causes of hospitalisation of studied group were chronic obstructive pulmonary disease (in 25\% of women, $53 \%$ of men). The other reasons for admitting to a hospital ward were hypertension (in $17 \%$ of women, $8 \%$ of men), diabetes type 2 (in $17 \%$ of women and $17 \%$ of men), asthma (in $17 \%$ of women, $8 \%$ of men). Furthermore, in the female group - psoriasis (7\%), acute myeloid leukaemia (7\%), Sjögren's syndrome $(7 \%)$ and in male group coronary artery disease $(8 \%)$, rheumatic polymyalgia $(8 \%)$ constituted reasons for hospitalisation.

Free-living elderly suffered mainly from hypertension (in $57 \%$ of women, $80 \%$ of men), hypercholesterolemia (in $43 \%$ of women, $30 \%$ of men), coronary artery disease (in $7 \%$ of women, $10 \%$ of men), hypothyroidism (in $17 \%$ of women). In addition gastritis (7\% of women), hiatus hernia (in 3\% of women, 20\% of men), Sjögren's syndrome (in 3\% of women), celiac disease (in 3\% of women), prostatic hyperplasia (in 10\% of men), chronic obstructive pulmonary disease (in 10\% of men) were present in freeliving elderly.

The inclusion criteria were: age $\geq 65$ and informed consent to participate in the study.

The exclusion criteria were: disagreement and lack of ability to cooperate, a severe condition of the patient making impossible to answer questions. People with cardioverter defibrillator were also excluded due to the inability to evaluate body composition by electric bioimpedance.

The work was performed as part of the research number 02-0048 and conducted in the Department of
Clinical Nutrition, Medical University of Gdansk. The study was approved by the University Ethics Committee.

\section{Methods}

The medical history was taken from all participants. Body height $(\mathrm{cm})$ and body weight $(\mathrm{kg})$ were examined. Based on the obtained data BMI $\left[\mathrm{kg} / \mathrm{m}^{2}\right]$ as weight $[\mathrm{kg}] /$ height $[\mathrm{m}]$ were calculated.

The measurement of hand grip strength was carried out using an analog hand-held dynamometer (Baseline 12-0240, USA) in the upright position, with the arm lowered along the torso and the dynamometer firmly in the palm of the hand. Norms for HGS $>20 \mathrm{~kg}$ for women and $>30 \mathrm{~kg}$ for men were adopted from The European Working Group on Sarcopenia in Older People (27).

Body composition was assessed by electric bioimpedance using the Maltron BioScan 920-2 analyser, which is a four-frequency device $(5 \mathrm{kHz}, 50 \mathrm{kHz}, 100 \mathrm{kHz}$ and $200 \mathrm{kHz}$ ). Four self-adhesive electrodes were placed on the right hand and right-hand skin. The measurement was done in the fasting state. The phase angle was tested at $50 \mathrm{kHz}$ (the value $\geq 8^{\circ}$ was considered as a norm).

For the evaluation of nutritional status, the full version of Mini Nutritional Assessment (f-MNA) was used. The patient was considered as well nourished when their f-MNA ranged between 24 and 30, as being at risk of malnutrition between 17 and 23.5 points and as having malnutrition if the score was less than 17 (25).

Appetite was evaluated by the Simplified Nutrition Assessment Questionnaire (SNAQ). Obtaining $\leq 14$ points indicated the risk of weight loss within 6 months (26).

Novel Frailty Index was used to assess frailty syndrome. This 5-question self-report questionnaire includes nutrition/shrinking, physical function, physical activity, forgetfulness and emotion/exhaustion. The answers are scored $0 / 1$ points, so the total score is from 0 to 5 points. When the patient received $\geq 3$ points, the syndrome was diagnosed (3).

\section{Statistical analysis}

Statistical analysis was performed with Statistica 12.0 for Windows. Distribution of variable was assessed with the Shapiro-Wilk test. The differences were tested with t-Student test or U-Mann Whitney test depending on the distribution of variables. Data are presented as the mean \pm standard deviation (SD) or median and ranges. $\chi 2$ Pearson test was also used. Analysis of correlations was performed using Spearman test. P-value of $<0.05$ was considered as statistically significant.

\section{Results}

In Table 2 comparative analysis of hand grip strenght and phase angle value are presented. Hospital patients had lower phase angle $\left(7.8^{\circ}\right.$ vs. $\left.8.8^{\circ}, \mathrm{p}=0.003\right)$. Hand grip strenght did not differ among groups (Tab.2). 
Table 2

Comparison of hand grip strenght and phase angle value among hospitalised and free-living elderly

\begin{tabular}{lcccc}
\hline $\begin{array}{l}\text { Mean } \pm \text { SD } \\
\text { or median (range) }\end{array}$ & $\begin{array}{c}\text { All subjects } \\
(\mathbf{n}=\mathbf{6 7})\end{array}$ & $\begin{array}{c}\text { Hospitalised elderly } \\
(\mathbf{n}=\mathbf{2 7})\end{array}$ & $\begin{array}{c}\text { Free-living elderly } \\
(\mathbf{n}=\mathbf{4 0 )}\end{array}$ & $\mathbf{p}$ \\
\hline HGS[kg] & $23(6-41)$ & $26(6-41)$ & $22.5(10-41)$ & 0.431 \\
Normal,n & $35(52 \%)$ & $14(52 \%)$ & $21(52.5 \%)$ & \\
Decresed, $\mathrm{n}$ & $32(48 \%)$ & $13(48 \%)$ & $19(47.5 \%)$ & 0.003 \\
Phase angle [ $\left.{ }^{\circ}\right]$ & $8.4 \pm 1.4$ & $7.8 \pm 1.8$ & $8.8 \pm 1$ & \\
Normal, $\mathrm{n}$ & $40(60 \%)$ & $9(33 \%)$ & $31(77.5 \%)$ & \\
Decreased, $\mathrm{n}$ & $27(40 \%)$ & $18(67 \%)$ & $9(22.5 \%)$ & \\
\hline
\end{tabular}

Legend: HGS- hand grip strength.

Table 3

The results of the nutritional status and NFI

\begin{tabular}{lcccc}
\hline${ }^{*}$ Median (range) & All subjects $\mathbf{n = 6 7}$ & $\begin{array}{c}\text { Hospitalised elderly } \\
(\mathbf{n}=\mathbf{2 7})\end{array}$ & $\begin{array}{c}\text { Free-living elderly } \\
(\mathbf{n}=\mathbf{4 0})\end{array}$ & $\mathbf{p}$ \\
\hline MNA $^{*}$ & $25.5(6-30)$ & $20.5(12-25.5)$ & $27.5(23.5-30)$ & $<0.001$ \\
Normal, $\mathrm{n}$ & $42(63 \%)$ & $4(15 \%)$ & $38(90 \%)$ & \\
Risk, n & $22(33 \%)$ & $20(74 \%)$ & $2(10 \%)$ & \\
Malnutrition, $\mathrm{n}$ & $3(4 \%)$ & $3(11 \%)$ & $0(0 \%)$ & $<0.001$ \\
SNAQ & $17(6-20)$ & $15(6-19)$ & $17(13-20)$ & \\
$>14 \mathrm{p}, \mathrm{n}$ & $53(79 \%)$ & $15(55 \%)$ & $38(90 \%)$ & \\
$\leq 14 \mathrm{p}, \mathrm{n}$ & $14(21 \%)$ & $12(45 \%)$ & $2(10 \%)$ & $<0.001$ \\
$\mathrm{NFI}^{*}$ & $2(0-5)$ & $3(0-5)$ & $1(0-4)$ & \\
$<3 \mathrm{p}, \mathrm{n}$ & $44(66 \%)$ & $10(37 \%)$ & $34(85 \%)$ & \\
$\geq 3 \mathrm{p}, \mathrm{n}$ & $23(34 \%)$ & $17(63 \%)$ & $6(15 \%)$ & \\
\hline
\end{tabular}

Legend: MNA- Mini Nutritional Assessment, SNAQ- Simplified Nutritional Appetite Questionnaire, NFI- Novel Frailty Index

\section{Nutritional Status and NFI}

In Table 3 results of full-MNA, SNAQ and NFI are summarized.

According to full-MNA results, $85 \%$ in the hospitalised group were malnourished or at risk of malnutrition. On the other hand, in the group of patients in the home environment, only $2 \%(\mathrm{n}=2)$ of the women and none of the men were affected (Tab.3).

The risk for significant weight loss ( $>5 \%$ in 6 months) assessed by the SNAQ ( $\leq 14 \mathrm{p})$ was also significantly higher in hospitalised patients.

Based on the NFI, the frailty syndrome was more common in hospitalised older patients than in free-living elderly, regardless of gender (respectively 63\% vs. 15\%, $\chi 2=22.3, \mathrm{df}=7, \mathrm{p}=0.002$ ).

Considering all studied elderly $34 \%$ of all subjects were recognized as a frail and $66 \%$ as a non-frail according to NFI. Significant differences between frail and non-frail elderly have been observed solely in age (respectively
$73.9 \pm 7$ vs $69 \pm 6, \mathrm{p}=0.01$,$) , phase angle value (7.8 \pm 1.8$ vs $8.7 \pm 1.2, \mathrm{p}=0.001)$, MNA [21 (6-29) vs $27(18.5=30)$, $\mathrm{p}=<0.001]$ and SNAQ [ $15(6-19)$ vs $17(12-20) \mathrm{p}=0.01]$ results. Frail elderly were older and in poorer nutritional status, had worse appetite and lower phase angle in comparison with non-frail (Fig.1).

\section{Analysis of the correlation}

Analysis of the correlation in the group of 67 elderly participants showed statistically significant associations of NFI score with age, the number of reported diseases, phase angle value and nutritional status (full-MNA). The age and number of reported diseases correlated positively. Conversely, the negative relationship was demonstrated for the value of the phase angle and the MNA score (data are shown in Table 4). 
Figure 1

Comparison of parameters of nutritional status, appetite in elderly with and without frailty syndrome according to Novel Frailty Index (NFI)

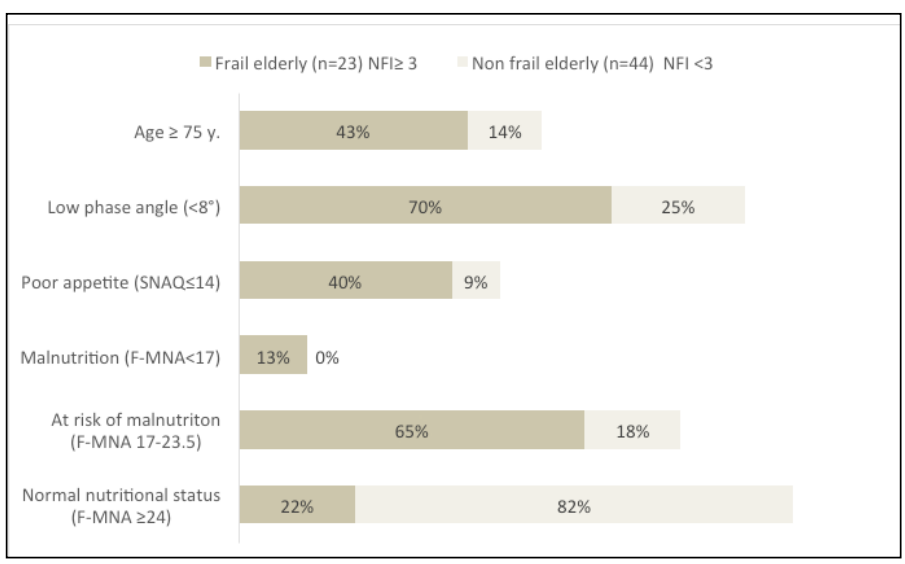

Table 4

The relationship between the Novel Frailty Index and components of the assessment of nutritional status

\begin{tabular}{lcc}
\hline Parameters $(\mathbf{N}=67)$ & R Spearman & $\mathbf{P}$ \\
\hline Age & 0.361 & 0.003 \\
Number of diseases & 0.295 & 0.016 \\
HGS[kg] & -0.151 & 0.224 \\
BMI [kg/m2] & 0.187 & 0.13 \\
Phase angle 50 kHz [ $\left.{ }^{\circ}\right]$ & -0.407 & $<0.001$ \\
Full-MNA & -0.515 & $<0.001$ \\
SNAQ & -0.184 & 0.135 \\
\hline
\end{tabular}

NFI- Novel Frailty Index, HGS- hand grip strength, BMI- body bass index, SNAQ- Simplified Nutritional Appetite Questionnaire, MNA- Mini Nutritional Assessment,

\section{Discussion}

Frailty in one of most burning problems in countries with aging populations and this issue recently focus more attention of both scientists and clinicians. There is no doubt that frailty implies increased morbidity and mortality and is connected with the need for long-term care (7-9). Despite all these unrelenting facts, we still didn't have a good screening tool to diagnose frailty or pre-frail state. Current methods of recognizing this syndrome require a number of tests, which often need to be performed by specialists $(2,13)$. That is why this study investigated the usefulness newly proposed by Yamada and Arai, self-reported 5-question screening index in association with markers of nutritional status, muscle mass, and strength.

The risk of developing frailty syndrome increases with age and it is often described as a physiological decline in late life $(14,15)$. Data from the Cardiovascular Health
Study $(\mathrm{n}=5317)$ demonstrated that discussed syndrome is more common in advanced age people. According to mentioned study, 3.2\% of free-living elderly in 65-70 age and $25.7 \%$ of those $\geq 85$ years were frail (7). Results of research presented in the paper show similar relationship. There was a statistically significant positive association of NFI values with age. Moreover, in comparative analysis, frail elderly were older than non-frail (respectively $73.9 \pm 7$ vs $69 \pm 6$ ) and the percentage of people $\geq 75$ years was higher ( $43 \%$ vs $14 \%$ ).

It should be highlighted that among hospitalised older people, the prevalence of frailty syndrome may be properly higher, due to often severe clinical condition, comorbidities, advanced age (16). Our study demonstrated that frailty syndrome was significantly more common in hospitalised older people than in community-dwelling elderly (respectively $15 \%$ vs 63\%). Furthermore, hospitalized respondents were affected with more chronic diseases, had a worse appetite and nutritional status, also men were older in comparison with free-living older people.

Many studies emphasize the strong correlation between malnutrition and frailty which were assessed by various diagnostic criteria (10-12). To our knowledge, the NFI has been used so far only by Suzuki et al. own to screen for frailty and its relationship with malnutrition in the elderly patients with chronic heart failure (4). Researchers have shown a statistically significant relationship between the NFI results and the MNA score $(r=-0,590, p<0,001)$. In our study group, we also found strong relationships between NFI and MNA ( $r$ $=-0.515, \mathrm{p}<0.001)$. Moreover, frail respondents were in worse nutritional status than non-frail elderly. It is worth pointing out, that $22 \%$ of frail elderly were wellnourished according to the full-MNA, which might indicate that the exclusive use of this assessment tool may be insufficient to identify the frail person. Boulos et al. published similar findings, where in a group of 399 frail participants $36.1 \%$ were well-nourished (17). Many authors describe malnutrition and frailty as related, but distinct conditions and both should be detecting (17-19).

Frailty syndrome is associated with decreased not only muscle mass but also muscle strength and power. Diagnostic criteria of this syndrome involve also evaluation of muscle function $(20,21)$. In the presented study, hand grip strength was assessed and the relationship between NFI and HGS was not recorded. However, a frequent decreased of HGS in both groups has been noticed. This may indicate the great need for nutritional status assessment not only hospitalized but also free-living elderly people.

The most important parameter measured in BIA is the phase angle (PA), which reflects the quantity of the cellular mass in the body, as well cell membrane function. The prognostic value of PA has been well established especially in severe health conditions i.a. in COPD, HIV, lung cancer or in dialysis patients and in relation to poor nutritional status $(22,23)$. In the Third National Health 
and Nutritional Examination Survey, in a sample of 4.667 older participants, showed that low phase angle was related to a four-fold higher odds of frailty among women and a three-fold higher odds of frailty among men (24). In the presented study the phase angle appears to be the most valuable parameter. PA positively correlates with NFI and is significantly lower in frail and hospitalized older adults in both genders.

In our opinion Novel Frailty Index is undoubtedly a simple tool for rapid screening and might be important in clinical practice in the future. The use of NFI does not require any special equipment for diagnostics. On the other hand, the tool requires a validation process. So far, there is too little data indicating the predictive value of this tool. Yamada and Arai examined 5852 elderly people living in the community and showed that the NFI can be a predictor of disability (3). Furthermore Suzuki et. al. indicated that NFI may predict poor outcome in chronic heart failure outpatients (4). Our study shows that the Novel Frailty Index is associated with a poor health condition, advanced age, poor nutritional status, lack of appetite and impairment of body cell mass. The important limitation of our study is the small sample of enrolled patients. Hence results of our study should be taken with caution.

\section{Conclusions}

Early diagnosis of frailty syndrome could be helpful to clinicians to potentially reduce the risk of complications connected with the implemented treatment, so we decided to assess in our study the new screening tool NFI. Preliminary results of our research indicate the relationship between the NFI score and the relevant parameters associated with the frailty syndrome (age, comorbidities, nutritional status, phase angle). Therefore, we highlight the need for further evaluation of NFI as a useful tool for screening of frailty syndrome.

Conflict of Interest: Nothing to disclose.

\section{References}

1. Główny Urząd Statystyczny. Ludność w wieku 60+. Struktura demograficzna i zdrowie.(http://stat.gov.pl/obszary-tematyczne/ludnosc/ ludnosc/ludnosc-w-wieku-60-struktura-demograficzna-i-zdrowie,24,1 html),downloaded 10.07.17r.

2. Stoicea N, Baddigam R, Wajahn J, Sipes AC, Arias-Morales CE, Gastaldo N Bergese SD. The Gap Between Clinical Research and Standard of Care: A Review of Frailty Assessment Scales in Perioperative Surgical Settings. Front Public Health. 2016;21;4:150.

3. Yamada M1, Arai H2. Predictive Value of Frailty Scores for Healthy Life Expectancy in Community-Dwelling Older Japanese Adults. J Am Med Dir Assoc. 2015; 1;16(11):1002.e7-11

4. Suzuki N., Kida K., Watanabe S., Kawashima Y., Ito C., Ashikaga K., Suzuki K., Omiya K., Harada T., Akashi Y.J.: Novel Frailty Index is Closely Related to Malnutrition in Outpatients with Chronic Heart Failure. Clinical Nutrition 2016; 35(S1): s.208
5. Vellas B., Villars H., Abellan G., Soto M.E., Rolland Y., Guigoz Y., Morley J.E. Chumlea W., Salva A., Rubenstein L.Z., Garry P.: Overview of the MNA - Its history and challenges. The Journal of Nutrition, Health \& Aging 2006; 10(6): s.456-463.

6. Cereda E.: Mini nutritional assessment. Current Opinion in Clinical Nutrition and Metabolic Care 2012; 15(1): s.29-41.

7. Fried LP, Tangen CM, Walston I, Newman AB, Hirsch C, Gottdiener J, Seeman T, Tracy R, Kop WJ, Burke G, McBurnie MA; Cardiovascular Health Study Collaborative Research Group. Frailty in older adults: evidence for a phenotype. J Gerontol A Biol Sci Med Sci. 2001 Mar;56(3): M146-56. PMID: 11253156.

8. Furtado G, Patrício M, Loureiro M, Teixeira AM, Ferreira JP. Physical Fitness and Frailty Syndrome in Institutionalized Older Women. Percept Mot Skills. 2017;124(4):754-776.

9. Mandelblatt JS, Cai L, Luta G, Kimmick G, Clapp J, Isaacs C et al. Frailty and long-term mortality of older breast cancer patients: CALGB 369901 (Alliance). Breast Cancer Res Treat. 2017;164(1):107-117.

10. Ferriolli E, Pessanha FPADS, Moreira VG, Dias RC, Neri AL, Lourenço RA Body composition and frailty profiles in Brazilian older people: Frailty in Brazilian Older People Study-FIBRA-BR. Arch Gerontol Geriatr. 2017;71:99104.

11. Artaza-Artabe I, Sáez-López P, Sánchez-Hernández N, Fernández-Gutierrez N, Malafarina V. The relationship between nutrition and frailty: Effects of protein intake, nutritional supplementation, vitamin D and exercise on muscle metabolism in the elderly. A systematic review. Maturitas. 2016;93:8999

12. Cruz-Jentoft AJ, Kiesswetter E, Drey M, Sieber CC. Nutrition, frailty, and sarcopenia. Aging Clin Exp Res. 2017;29(1):43-48.

13. Laur CV, McNicholl 1, Valaitis R, Keller HH. Malnutrition or frailty? Overlap and evidence gaps in the diagnosis and treatment of frailty and malnutrition. Appl Physiol Nutr Metab. 2017;42(5):449-458.

14. Clegg A, Young J, Iliffe S, Rikkert MO, Rockwood K. Frailty in elderly people. Lancet. 2013;381:752-762.

15. Chen X, Mao G, Leng SX. Frailty syndrome: an overview. Clinical Interventions in Aging. 2014;9:433-441. doi:10.2147/CIA.S45300.

16. Oliveira DR1, Bettinelli LA, Pasqualotti A, Corso D, Brock F, Erdmann AL. Prevalence of frailty syndrome in old people in a hospital institution. Rev Lat Am Enfermagem. 2013;21(4):891-8.

17. Boulos C, Salameh P, Barberger-Gateau P. Malnutrition and frailty in community dwelling older adults living in a rural setting. Clin Nutr. 2016;35(1):138-43.

18. Laur CV, McNicholl T, Valaitis R, Keller HH. Malnutrition or frailty? Overlap and evidence gaps in the diagnosis and treatment of frailty and malnutrition. Appl Physiol Nutr Metab. 2017;42(5):449-458

19. Bollwein J, Volkert D, Diekmann R, Kaiser MJ, Uter W, Vidal K, et al. Nutritional status according to the mini nutritional assessment (MNA®) and frailty in community dwelling older persons: a close relationship. J Nutr Health Aging.2013;17(4):351e6

20. Frailty in Older People. Lancet. 2013;381(9868):752-762. doi:10.1016/S01406736(12)62167-9.

21. Cesari M, Leeuwenburgh C, Lauretani F, et al. Frailty syndrome and skeletal muscle: results from the Invecchiare in Chianti study. The American journal of clinical nutrition. 2006;83(5):1142-1148.

22. Gupta D1, Lis CG, Dahlk SL, Vashi PG, Grutsch JF, Lammersfeld CA Bioelectrical impedance phase angle as a prognostic indicator in advanced pancreatic cancer. Br J Nutr. 2004;92(6):957-62.

23. Kyle UG1, Genton L, Pichard C. Low phase angle determined by bioelectrical impedance analysis is associated with malnutrition and nutritional risk at hospital admission. Clin Nutr. 2013 Apr;32(2):294-9.

24. Wilhelm-Leen ER1, Hall YN, Horwitz RI, Chertow GM. Phase angle, frailty, and mortality in older adults. J Gen Intern Med. 2014 Jan;29(1):147-54.

25. A guide to completing the Mini Nutritional Assessment. (http:/ / www.mnaelderly.com/forms/mna_guide_english_sf.pdf), downloaded 20.07.2017r.

26. Wilson MM, Thomas DR, Rubenstein LZ, Chibnall JT, Anderson S, Baxi A Diebold MR, Morley JE. Appetite assessment: simple appetite questionnaire predicts weight loss in community-dwelling adults and nursing home residents. Am J Clin Nutr 2005; 82: 1074-1081.

27. Cruz-Jentoft AJ, Baeyens JP, Bauer JM, et al. Sarcopenia: European consensus on definition and diagnosis: Report of the European Working Group on Sarcopenia in Older People. Age and Ageing. 2010;39(4):412-423. doi:10.1093 ageing/afq034 